\begin{tabular}{|l|l|r|}
\hline Volume 3, Number 11 & Novel Theory & 20 JUNE 2019 \\
\hline
\end{tabular}

\title{
A Grounded Theory Study: From the Barn to the Boardroom
}

By

Robyn Lord, University of South Florida

C hange management is at the forefront of many business leader's minds and at the evitable yet change for many is a very hard task. The Wall Street Journal reported in 2017 that the U.S. spent $\$ 63.2$ billion on consulting costs, which is an $8.1 \%$ increase from $\$ 58.7$ billion in 2016 (Shumsky, 2018). Many companies pay for high-level consultants to help with organizational change. Many business leaders do not have expertise in that area and find it difficult to administer change within an orga-

nization. The flip side to that scenario is that once the change proposal is in place, many employees fail to comply. The purpose of this study is to uncover the underlying beliefs that could affect why people resist change. The last thing a company wishes to do is waste valuable funds on changes and then have very few abided.
It may be possible that the resistance to change is related to the long-standing belief systems that are already in place. A grounded theory study was conducted on the equine industry to uncover the reasons why some people are adopting or resisting change in an industry that has not seen change in hundreds of years. The equine industry is a unique study model that has virtually stood the test of time, unchanged for centuries, and still strong. The industry saw a shift in core beliefs roughly thirty years ago, and this new belief system is converting adopters in ways that is creating a new lifestyle. By uncovering the reasoning of those who resist or adopt change, this research will shed some light on the core human reactions to change. These core beliefs can be applied to any business model through a new grounded theory proposed in this research.

Keywords: Change Management, Status Quo, Grounded Theory, Resistance to Change, Organizational Change

Copyright ( 2019 , Robyn Lords. This article is published under a Creative Commons BY-NC license. Permission is granted to copy and distribute this article for non-commercial purposes, in both printed and electronic formats 
It has been said that a human being has an attention span of eight seconds, which is down four seconds from the year 2000. It is also said that the goldfish has the attention span of nine seconds. People's attention spans are growing shorter, and they're asked to adapt to change much more quickly. According to research, the human being is bombarded with mass amounts of information daily. How can managers use the right techniques to promote positive change in their corporations with full buy-in from their employees? Most reasons why people resist change include: fear of the unknown, mistrust, or being set in their ways. Most people won't change unless they know what's in it for them. The time it takes to persuade an employee to understand the benefits of a change may be too high a cost for many corporations. Corporate change is sometimes necessary for a short time frame. Change is often beneficial to avoid stagnation and with the internet surpassing all virtual expectations--change is inevitable.

The research presented in this study is built around a proposed paradigm shift within an industry. As we know, paradigm shifts are slow and can take up to a decade to exhibit a full adoption. This research dives deeply into the equine industry that has been historically stagnant for centuries. While this stagnation is apparent, it is also prideful. Members of this industry are in an "If it isn't broke, don't fix it." mentality strengthened by the "It's the way we've always done it, why stop now?" reasoning. The fascination towards such an industry is at the core of this grounded study research. The research focuses on the core long-standing belief systems that have guided this industry through wars, industrial revolutions, and athletic prowess. Even as the horse itself has changed its purpose, the beliefs of the industry have been left unscathed and unchanged. It was not until a phenomenological change had taken place roughly thirty years ago when the industry was abruptly changed into divided factions of natural versus traditional in hoof care and horsemanship. The industry is shifting, yet some dig their boots in and resist with vehemence. The research will focus on this industry model, specifically on the resisters. A grounded theory model is presented to help to facilitate the understanding of why people may resist change.

\section{Findings}

Results from a recent article, "A Qualitative Approach to Understanding Adoption or Resistance of Long-Standing Belief Systems within the Equine Industry" (Lord, 2019) reveal that the elevated codes provide evidence of universal characteristics and traits exceptional to each group. They were not broken out to each faction, but each node included possible beliefs from all 41 interviews. Tables 1 and 2 are the top categories and concepts within each faction. What was particularly interesting through the
Table 1. Traditional Patternistic Coding Results to Second-Tier Coding

THC

\begin{tabular}{|c|c|}
\hline Categories & Concepts \\
\hline Welfare & Protection \\
\hline Closed Mindedness & Governing Principle \\
\hline Status Quo & Time Tested \\
\hline Limitations & Domestication \\
\hline Dependency & Euphanistic \\
\hline Conformity & Existing Conditions \\
\hline Personal Development & Pride of Place \\
\hline Economic & Standards \\
\hline Legislation & Regulations \\
\hline \multicolumn{2}{|l|}{ THP } \\
\hline Categories & Concepts \\
\hline Welfare & Harsh Treatment \\
\hline Economy & Value \\
\hline Protection & Safety \\
\hline Personal Dev. & Pride of Place \\
\hline Status Quo & Time Tested \\
\hline Power Dynamic & Class Status \\
\hline Control & Submission \\
\hline Communication & Relationship \\
\hline
\end{tabular}

Table 2. Natural Patternistic Coding Results to Second-Tier Coding

\begin{tabular}{ll} 
NHC & \\
Categories & Concepts \\
\hline Acceptance & Adopter \\
Validation & Affirmation \\
Compromise & Last Resort \\
Strategy & Market Trends \\
Pro-Active & Protocol \\
Open mindedness & Alternatives \\
Protection & Safety \\
Self Preservation & Conflict \\
Enlightenment & Education \\
NHP & \\
Categories & Concepts \\
Psychology & Interaction \\
Protection & Safety \\
Mindfulness & Awareness \\
Trustfulness & Priority \\
Market Share & Success \\
Welfare & Better Care \\
Patience & Steps to Action \\
Competition & Niche Division \\
Role Modelling & Desired results \\
Sense of Family & Partnership \\
Social Norms & Question Tradition
\end{tabular}




\section{Methodology}

According to Charmaz (2014), grounded theory methods consist of systematic, yet flexible guidelines for collecting and analyzing qualitative data to construct theories from the data. Grounded theory begins with inductive data, invokes iterative strategies of going back and forth between data and analysis, uses comparative methods, and keeps you interacting and involved with your data and emerging analysis (Charmaz, 2014). Gathering data is the most important part of this qualitative and sometimes mixed methods research model. For this qualitative research, 41 industry experts were interviewed in a semi-structured format. The industry was broken into the two opposing viewpoints in question, and then represented the two major factions within the industry. This analysis ended up being a four-faction analysis process. The key to the research was to identify the problem or industry phenomenon, assemble the most diverse, industry efficient group of leaders, gather the data responses, and elevate the coding to a selective theory level to create a grounded theory as seen in Figure 1.

\section{Data Collection}

Data collection began with a pilot study on January 24,2018 . Once the qualitative questions were validated, the process of participant selection began. To be fair to the study, the industry must be represented in as manv industrv leaders as possible. To mimic the level of leadership and organization development,

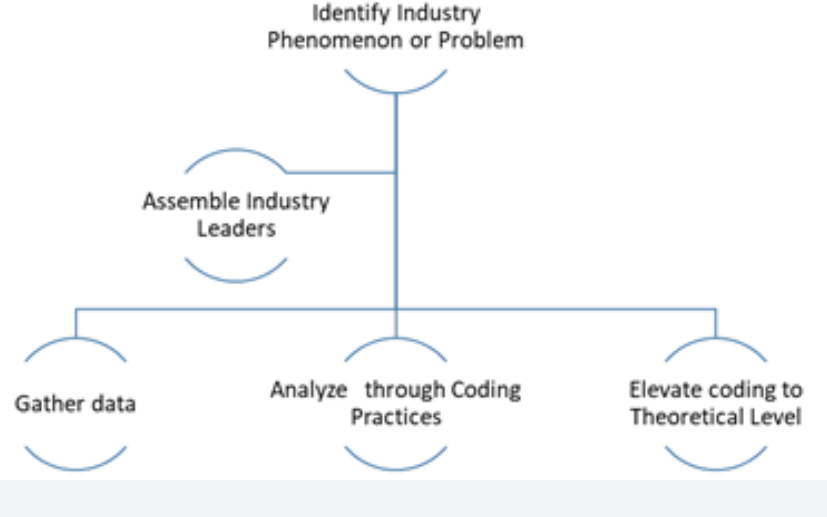

Figure 1. Grounded Theory Process of Data Collection the participants must be in a professional leadership role within the industry, acting as a role model or expert in the field. Also considered were the second level management professionals that are participating in the industry as either an adopters or resisters. This included members such as the veterinarians, scholars, and iconic equine figures, clinicians, Olympic professionals, professional competitors, as well as leaders of major industry corporations. The outcome should represent not only those resisting or instilling adopting, but also those professionals (role models) who are in the field and experiencing the friction from the two opposing viewpoints.

Interviews were conducted in January 2018 and were finalized on May 13, 2018. All but 10 interviews were conducted in person as three were international participants, and seven were out of state at the time of this study. The average interview was 44.22 minutes long with the longest interview being 77.49 minutes. All interviews were transcribed and edited for correct content. Most leaders were chosen for their prominence in the industry and their identification with either natural or traditional beliefs. Many participants were recommended by those leaders or heard about the study and wanted to participate. The overall response from the industry was positive and respondents were sincerely interested in the study results. The friction within the industry is ever-growing causing regulations, legislation and governance to be questioned. This unique opportunity lends itself nicely to the overall goal of understanding the long-standing belief system in the context of resisting or adopting change.

The analysis process began with the transcripts $1-41$. The coding process took on two forms: NVivo 12.0 and hand coding. The transcripts were open coded in NVivo software. NVivo proved to be a great sorting tool to capture the lineby-line analysis. Sixty-one (61) nodes (codes) were created in NVivo with 14 child nodes. At the same time each interview was coded in NVivo, it was also hand coded. The act of hand coding allowed for the memo writing portion to take place. In advance, it was necessary to recognize the tools of the grounded theory. Most grounded theory research is void of any hypothesis. Therefore, the selective coding or theorizing is done mostly from the memos written from the initial transcripts. This was done in the beginning to streamline the process. Figure 2 demonstrates the iterative design and the interactive relation-

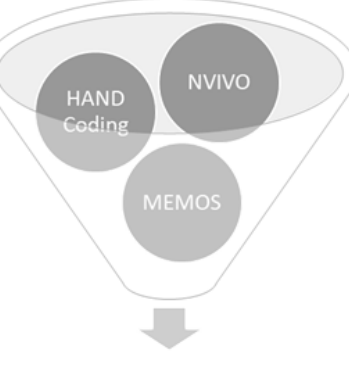

Selective Coding $=$ Theory ships of the grounded theory process.

Figure 2. Data Synthesis of Grounded Theory 
data collection and analysis was the order in which the repetitive or universal beliefs were valued. The categories are in descending order. An example of a noteworthy topic of discussion is the characteristic of welfare. It would be an obvious assumption to predict that people in the traditional and natural hoof care and horsemanship factions are taking the welfare of the horse in mind when discussing belief systems.

However, the traditional horsemanship and hoof care members listed welfare as the most important belief system. The natural hoof care members listed welfare in a lower ranking, while natural horsemanship members listed protection, not welfare as a top belief response. Welfare was not a top priority, which was surprising, and yet very indicative of the new shift in the long-standing belief systems of the equine industry. While welfare was the main response within the traditional faction, their belief system lies within the strict guidelines of protecting the horse at all costs and that domestication has forced them into the status quo mentality of tradition. They make light of the dependency on their belief system through euphemisms. The traditional factions are very prideful of their

beliefs and control their situation through traditional cultural viewpoints.

Status quo was a highly ranked response for traditionalists, as assumed. The traditionalist members were particularly concerned about personal development. This became important in the formation of the business model for adoption and resistance found later in this article. Personal development was discussed during the interview process in terms of self-assessment, mentoring, and sharing of information amongst the group. The natural members did not rate personal development at all. They were more concerned with mindfulness, trusting, and the power dynamic. What was revealed during the study was an awakening of the industry and resurrection of the belief system towards the value of the industry to themselves and to others. It was not particularly about sharing the knowledge, nor was there a large indication of respect to the elders of the industry. Unlike the traditional faction, the natural members were concerned on a more mindful level, with validation, psychology, and acceptance representing the top criteria for discussion.

The natural faction demonstrated areas of affirmation and adoption of the new belief system. They tended to proclaim their beliefs more readily and at the forefront of most conversations. They are proactive and are dedicated to the new belief system. Their main priority is the relationship being built through mindfulness and maintained in a stress-free manner for both participants. They feel the shift is increasing in numbers and more concerned with well-being than a sense of family. Welfare is also important to this faction, although lower in rank than the traditional faction.

The traditional belief systems were isolated in the process of focused coding when applied to the categories in Tables 1 and 2. Through this level of the process, their association with the belief system and its origin was recorded and first generation, yes or no. At this stage, it was not known whether this was a factor contributing to the resistance or adoption factor. Each section within Tables 3 and 4 is divided into Traditional-Resisters and Traditional-Adopters. This is going to be important in the next phase of analysis.

For this study, it was not necessary to delve into the details of the industry itself as this was covered in previous articles. What is important are the results of the resisters and adopters. Also important is the phenomenon discovered that divided the traditional section into Traditional-Resisters and Traditional-Adopters. Research uncovered a "hybrid" identifier that was not anticipated. This is the reflection of traditional resisters who are leaders in the long-standing belief system as status quo yet have taken on some tendencies of adoption. The research revealed an "adapt before adopt" clue that may be pertinent to the model development.

The advanced phase of axial coding revealed the Faction Variances. This is the complicated portion of the coding and this procedure was a bit different than what was found in most coding projects. The participants were classified as either T-R (traditional, resister) or T-A (traditional, adopter at some level). The memos discussed in the beginning of the data collection process were compiled by hand coding original transcripts. Phase three took the participant segregation and compared it to the Memo secondary coding for categories. Table 4 demonstrates the results that were received for selective coding through memos. According to Creswell (2013), the memo writing process becomes part of the development of the theory as the researcher writes down ideas as data are collected and analyzed. In these memos, ideas attempt to formulate the process that is being seen by the researcher and to sketch out the flow of the process. The memo coding was cross-referenced with the emergent categorical data to reveal attributes that enhanced the coding process by adding properties and dimensions. There was a total of 43 axial categories in the Traditional Hoof Care Group 
Table 3. Axial Coding

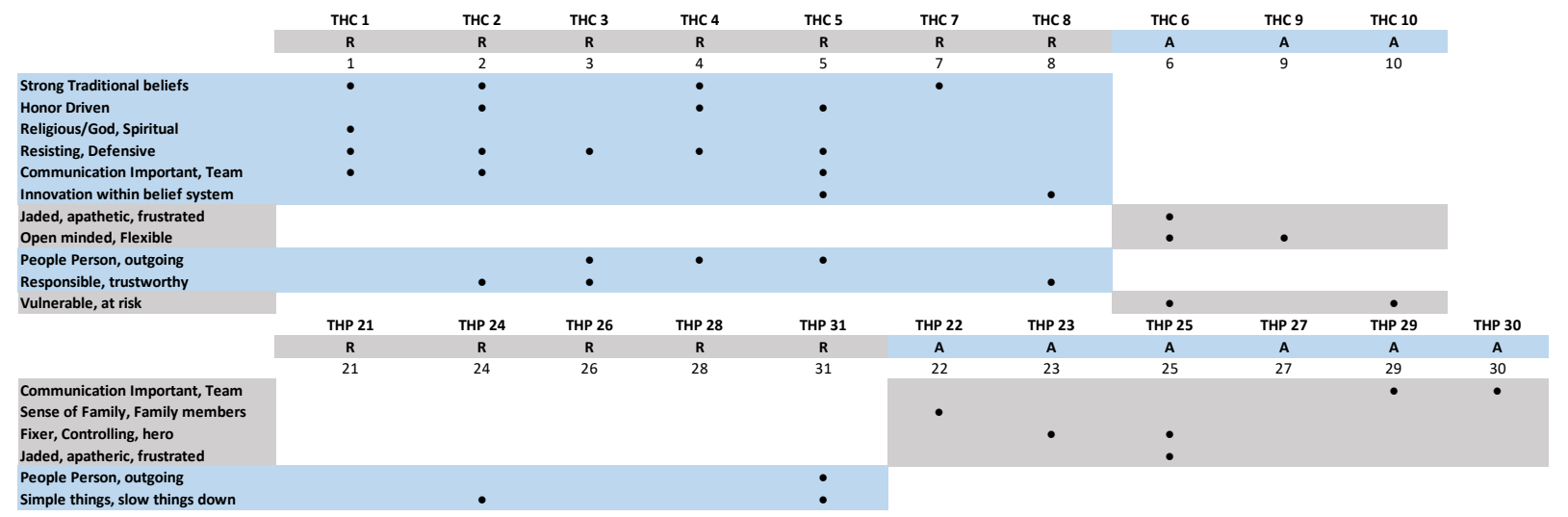

and 38 axial categories in the Traditional Horsemanship Group. This is the stage in the process called Axial Coding. Areas highlighted demonstrate the beliefs that belong to those traditional participants: Traditional-Resister and not Traditional-Adopter. The table is divided into two sections, Resister ( $\mathrm{R}$ ) and Adopter (A). Table 3 shows the results that matter to the study and the characteristics that are present in one group, but not the other.

Table 4 is the grid comparison phase that compiles this data in the axial version and creates a themat-

Table 4. Theory-Driven Selective Thematic Coding ic vision for the proposed theory. The analysis was completed on an inclusive and selective method. The bias of the data was revealed in these four quadrants. It was important to compare Traditional-Resister Hoof Care to Horsemanship as well as Traditional-Adopter Hoof Care to Horsemanship. These comparisons procured the results of possible traits that are believed to be reliant on the long-standing belief systems. Another comparison was made also with Traditional-Adopter Hoof Care to Traditional-Resister Hoof Care as well as Traditional-Resister
T-R THC

Strong Traditional beliefs

Honor Driven

Religious/God, Spiritual

Resisting, Defensive

Communication Important, Team

Innovation within belief system

People Person, outgoing

Responsible, trustworthy

T-A THC

Jaded, apathetic, frustrated

Open minded, Flexible

Vulnerable, at risk
T-R THP

People Person, outgoing

Simple things, slow things down

T-A THP

Communication Important, Team

Sense of Family, Family members

Fixer, Controlling, hero

Jaded, apatheric, frustrated 
Horsemanship to Traditional-Adopter Horsemanship. This research is looking at the causal relationships between those who only resist, and those who adopt at a minimal level. Table 4 demonstrates the relationship between the comparison grids and fully articulates the four levels of analysis. What is interesting is the one factor that is common to each group Traditional-Resister, referencing people as being important for resisters and Traditional-Adopter members owning traits as jaded and apathetic towards the industry in some respects. The theory at this point is starting to evolve. There will be more on this topic in the next section on the proposed theory.

Elevation of the coding process enables the research to draw on the qualitative data outcomes and produce areas of interest. This is a macro look at the industry model used in the research. From this research, it can be deduced that there is significance evidence to support the findings that people who resist change may have these characteristics or traits in their belief system: Strong Traditional Beliefs such as culture and histo-

ry, honor-driven, strong religious ties, defensive by nature, communicate well, believe in safe, minimal adaptation (innovation), consider themselves to be trustworthy and responsible, are people-oriented and outgoing, and enjoy the simple things. According to this research, people with those traits and characteristics are more apt to resist change and may be a potential problem when instituting change in an organization.

Consequently, this research also points towards the significant evidence to support the findings that people who resist change may have these characteristics or traits in their belief system: frustration in industry or a sense of apathy, open-mindedness or flexibility, vulnerability, communicate well, family ties, like to control and be the hero through helping.

It can also be stated that there is significant evidence to support the findings that for those who are traditional by nature, but when compared to the traditionalists who showed tendencies for adoption at any level, may have come to the realization that the industry is flawed and through frustration, may have allowed flexibility and an open-minded nature to evolve where one did not exist previously. Many participants allowed for extensive vulnerability to permeate the interview process. The theme of vulnerability is an opaque veil of security while adopting in a small way. There is also significant evidence that demonstrated that those who are resisters are people driven and outgoing, concerned with education and supporting traditional beliefs. They also wanted to keep things simple--almost honoring the old days of history. Many discussed retirements and wanting to make the business smaller, not larger. For those in that group who adopted, there is significant evidence to support the finding that being a team player, communicating and having a sense of family is more important than just any random group of people. Adopters might be adopting to support a sense of belonging and wanting to be the hero in their group. Again, the adopters showed apathy and frustration which may have been the vehicle for even the slightest adoption within their traditional network.

\section{The Proposed Theory}

Through all the iterations of analysis and cross-analysis, a theory emerges. The research goal is to produce a theory to support the business realm of change management. To the original title, barn to boardroom, this research procured a theory based on long-standing belief systems. Long-standing belief systems are difficult to identify through origin but are clearly defined within these groups.

The industry studied had long-standing beliefs that would prevent those from adopting any type of new beliefs. The theory being proposed will encompass the resisting beliefs as outlined within the entire qualitative process. Figure 3 is an overview of the new theory hybrid adaptation theory. This theory encapsulates the findings in this grounded theory research. As change is inevitable and hard to sustain, the hybrid change model allows for long-standing belief systems to influence the exposure to new beliefs.

The nature of questioning the status quo is an important part of this process. The weighing of the adoption as a threat or risk may be a factor for resistance. The approval process of adoption begins with the precursor of adapting first, then adopting. As discussed previously in the article, "The Equine Industry: Competing Beliefs, Change and Conflicts" (Lord, 2019), the newly formed shift of an industry which has been stagnant to change for decades showed evidence of change through the evolution of a new belief system. It was concluded that the industry had been divided into two main camps of resisters and adopters. Along the lines of change, 


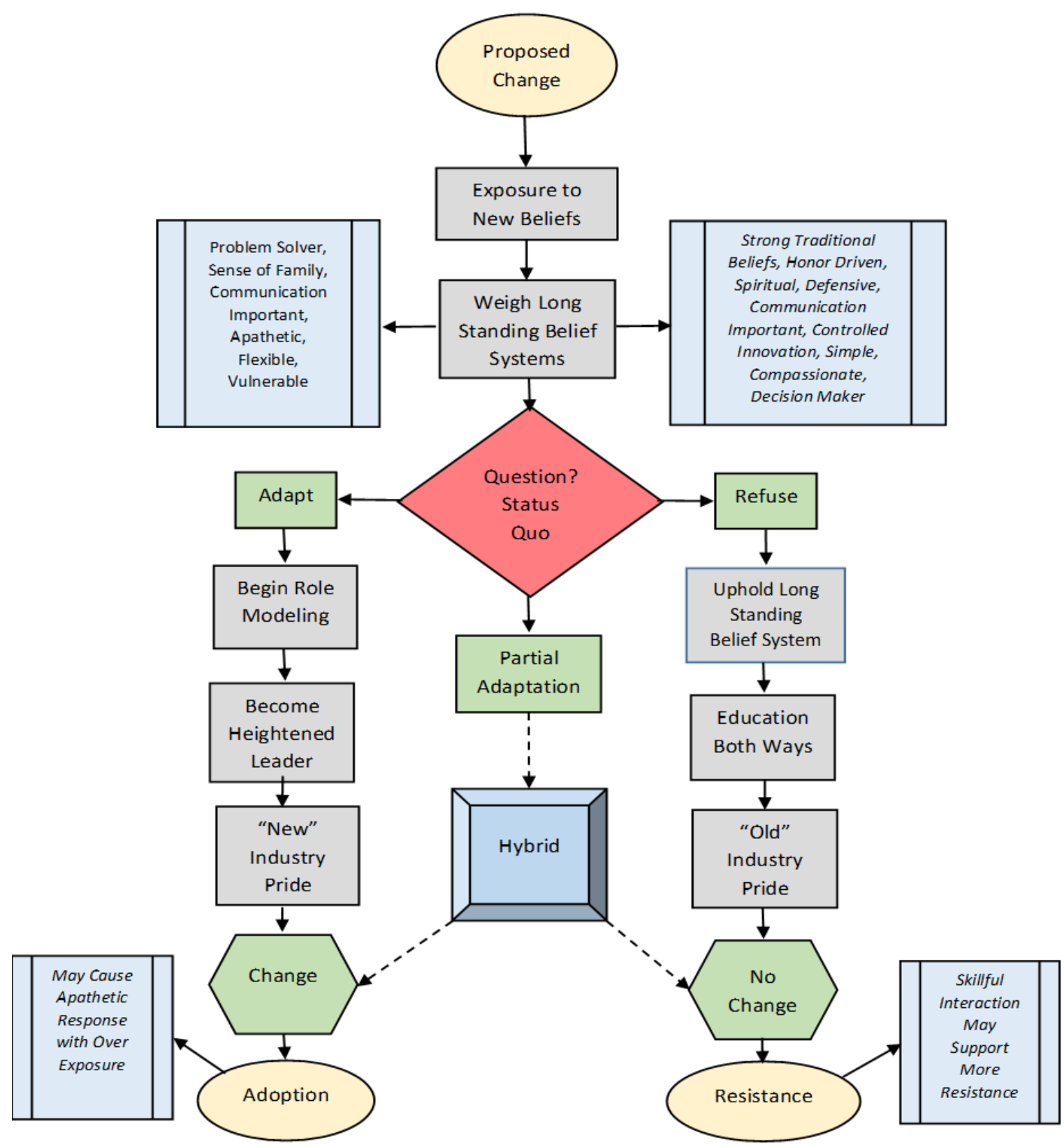

Figure 3. Hybrid Adaptation Theory

the model evolved from the industry analysis and determined that long-standing belief systems can be changed. The moment of first change can be demonstrated in the hybrid model through the adaption phase. Critical to the belief that adaption is not a permanent change but a temporary change that can become permanent, hybrid, or revert to its original belief system through resistance. There is significant evidence in this research data that the adapting is where adoption begins as can be seen in the hybrid model.

The hybrid concept proved to be interesting in the pretense of status quo acceptance or resistance.
Weighing of the belief system was the moment in time in the model where long-standing belief systems are either gaged as resistors or acceptors. Following the Table 4 results--adapt, refuse or partial adaptation divides the business model into three distinct and directive areas of change. The desired result would be adapting to the proposed change. Adapting is a form of transformation according to recent definitions. Most business models define adapting as being agile or flexible. This theory is proposing that the flexibility is inadequate when it comes to long-standing belief systems. The inadequacy falls into play when flexible can also mean 
revert. In most definitions, flexible (agile) means easily changed without much thought. Although that can be assumed to be a long-standing belief system characteristic, for the purpose of this research, agility and flexibility would fall into the 'hybrid' adaptation area, and not a solid adoption result. This could translate into a negative business development when proposing a change. This research provided evidence where the weighing of the long-standing belief system is the critical point in the model.

Evidence in this theory also demonstrates a tendency for the traditional resisters who uphold the traditional belief systems to educate others and vice versa. The adoption side of this model did not seem to articulate the need for education as much as resistance to traditional beliefs through leadership. Their education did not seem to go both ways but rather presented itself in a leadership style of education through role modeling. Evidence also showed that industry pride in the form of honor-driven beliefs or sense of family demonstrated the overwhelming response. Industry pride has a lot to do with change management. Pride for the organization, pride for the management team, or basic pride for your industry, each facet is important to the change process and should be the deciding goal in the process of change when dealing with long-standing belief systems. By taking the long-standing beliefs into account early in the process, the rate of adoption is dependent on the adaptation rate and can positively affect the outcome of acceptance (adoption).

\section{Applications of the Theory}

The Hybrid Adaptation Model can be utilized in most proposed organizational changes. It would stand to reason that when change is questioning beliefs that risk the safety of the individual in areas such as family and spirituality, the resist factor will be heightened. Heightened resistance will eventually lead to refusal of the proposed change.

The following list is a set of checkpoints to the proposed hybrid adaptation theory and can be used for the application process. The object is to minimize the resisting factors and optimize the adopting factors. Through minimization, the long-standing belief systems are addressed. When utilizing this model and proposing change, it is important to:

$\checkmark \quad$ Include areas where honor or awards are part of the process

$\checkmark \quad$ Navigate the change proposal through family group dynamics to strengthen the process
Communication is important, stay transparent and avoid problems

$\checkmark$ Recognize the outgoing personalities who require a hero position

$\checkmark$ Value the responsibility and trust, allow added leadership roles

$\checkmark$ Share the vision as the universal unit of belief with traditional values

$\checkmark$ Take advantage of the flexibility of participants by fostering creativity

$\checkmark$ Avoid frustration and apathy by having accountability of the members

$\checkmark$ Begin with introduction of innovation within the framework when proposing change

$\checkmark$ Foster the hybrid factor where adaption is the phase before adoption

Most organizations want to allow for change and innovation. However, it is up to the management style of the organization to provide the strongest message. In a recent journal article on change management, it was stated that firms not only need the right type of manager, but they also need the appropriate communication style. Further research described the support of the people-oriented attribute and recognizing the need for results. However, in this study, results-oriented managers had a higher probability for change, where people-oriented managers had a slightly lower probability for change (within a $10 \%$ range) (Bel, Smirnov, \& Wait, 2018). The addendum to the checklist

should also include:

$\checkmark$ Allocate change management to results-oriented management for a higher probability for change

$\checkmark \quad$ Establish communication styles for results-driven management

\section{Discussion}

As discussed previously, change is a part of everyday life. The level of change or adoption is dependent on the level of the long-standing belief systems within that industry. There are many reasons why most people resist. On a macro level, the research proposed that fear may be a factor contributing to the steadfast attachment to tradition. When resisters are looking at the options to adopt, the attachment level is honor (respect) driven. The qualitative data suggests that distinction and recognition is important. Subsequently, when resisters are more apt to adopt, the attachment level is vulnerability (frustration) driven. Looking closely at the data provided insights that were surrounding these primary indicators-when you think about it, isn't lack of honor a state 
of vulnerability or possible area of threat? When you feel vulnerable, isn't that when you are most open to suggestions or most impressionable? It would be important for change management professionals to see the benefit of honor-driven adoption plans where frustration with the status quo is recognized, not minimized. The ability to change is dependent on the understanding and control of these factors. As without the control during a change phase in an organization, the frustration can backfire and cause more problems than the solution.

\section{Conclusions}

Organizational change is a highly revered topic of discussion amongst management professionals. The ability to propose a change and ensure its full adoption with the current employee roster is close to impossible. Some will resist the change and either leave or be let go. Others will adopt the change only to revert or adopt portions in a short amount of time. Very few organizations can guarantee a full adoption process during change. People resist change innately and with the bombardment of technology and information, people are far less apt to devote the resources to change as quickly as we would like as professionals. People are asked to change over and over through technology and innovation on a regular basis. One might think it would stand to offer security for change becoming more accepted. However, corporations are spending billions of dollars on consultants to assist in the change process.

This research proposed to investigate an industry that is unique and has not changed in centuries during all this innovation. The beliefs are historically entrenched in tradition, wrapped in historical content, and until recently (in the last twenty years), nothing had changed. Within the past two decades, a new belief system was introduced proposing a shift in the traditional belief system, resulting in friction amongst the factions. Resistance became more pronounced, and adoption was on the uphill swing. Qualitative research provided the framework for a new theory of utilizing these belief systems from the beginning and understanding more completely how the belief systems play a role in the choice of adoption or resistance.

This research will show significant evidence that attempts to answer the questions: Why do some people resist change? What are the innate traits that are evident in one group, yet absent in the other? The two groups being studied are the traditional and natural members of the equine industry. Not many oth- er industries can say that they have not changed over time, even in the face of industrial revolution, war, and domestication. This industry study, through qualitative data collection, provided a direct line to the beliefs that people have, yet do not know where they came from. Most beliefs within the industry are just there, it was the status quo, and generally no one prior to two decades ago questioned anything. Prior to two decades ago, everyone was part of the same family of horse people. We all got on the horse from the left, no questions asked. The grounded theory method provides the pathway to uncovering the beliefs that are embedded.

This research also supports the premise that a phenomenon exists, the industry is being challenged and the industry is divided. The data also provides confirmation to these observations and creates an identifier that can be used to synthesize the data in the second phase of coding. The data itself was coded both by hand and in NVivo. The NVivo software was integral in sorting the data. However, the grounded theory method which gains its validity through the memos and development of theory could be attained through NVivo. The data was also cross-referenced and compared on a micro and macro level. The selective macro coding provided attributes and traits that are present with those who resisted the new belief system as well as providing a new "hybrid" link to resisters who were adopting on a small scale. It was believed that this 'hybrid' adoption could be the precursor for tipping the belief in the future towards adoption. Managers can benefit from looking more closely at long-standing belief systems. They play an integral role in why people are more likely to adopt or resist change. The goal of understanding these concepts is to possibly speed up the change process, gain adoption more quickly, more permanently, and at a lesser cost to the firm.

\section{References}

Bel, R., Smirnov, V., \& Wait, A. (2018). Managing change: Communication, managerial style and change in organizations. Economic Modelling, 69, 1-12. https://doi.org/10.1016/j.econmod.2017.09.001

Charmaz, K. (2014). Constructing grounded theory: A practical guide through qualitative analysis. (2nd ed.). London; Thousand Oaks, CA: Sage Publications.

Creswell, J. W. (2013). Qualitative inquiry \& research design: Choosing among five approaches. 
Los Angeles, CA: Sage Publications.

Lord, R. (2019). Qualitative approach to understanding adoption or resistance of long-standing belief systems within the equine industry. Muma Business Review,

Lord, R. (2019) The equine industry: Competing beliefs, change and conflict. Muma Business Review,

Shumsky, T. (2018, June 6). U.S. Consulting fees climb to $\$ 63.2$ billion in 2017 on tax, digital transformation [Blog post]. Retrieved from https:// blogs.wsj.com/cfo/2018/06/06/u-s-consultingfees-climb-to-63-2-billion-in-2017-on-tax-digital-transformation/.

\section{Review}

This article was accepted under the constructive peer review option. For futher details, see the descriptions at:

http://mumabusinessreview.org/peer-review-options/

\section{Author}

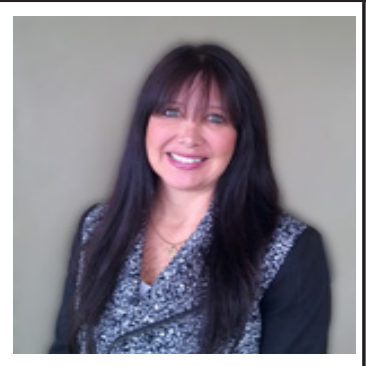

Robyn Lord is the Co-Founder and CEO of the Institute of Applied Equine Podiatry, Inc. in Naples, FL. Lord oversees all business and program development, product development, as well as student recruitment and assessment. Currently, the institute has graduates in over 18 countries. Lord received her BS in Business Administration from Castleton State College in VT (1999) with High Honors, an Executive MBA from Florida Gulf Coast University in FL (2015) and a Doctorate in Business Administration (DBA) from University of South Florida in Tampa (2018). 